\title{
Treadmill exercise improves spatial learning ability by increasing cell proliferation in offspring born to maternal rats receiving stress during pregnancy
}

\author{
Tae-Woon Kim', Young Jun Ko², Ki-Hyok Youn³ , Boo-Geun Hwang' ${ }^{4}$ Hyun-Seok Bang ${ }^{4}$, Sam-Jun Lee,** \\ 'Department of Human Health Care, Gyeongsang National University, Jinju, Korea \\ ${ }^{2}$ Major in Sport Service Practice, College of Welfare Convergence, Kangnam University, Yongin, Korea \\ ${ }^{3}$ Department of Social Welfare, College of Health, Welfare and Education, Tongmyong University, Busan, Korea \\ ${ }^{4}$ Department of Sport Rehabilitation, College of Health, Welfare and Education, Tongmyong University, Busan, Korea
}

Prenatal stress causes learning deficits by inhibiting neurogenesis in the hippocampus. We studied the effects of maternal treadmill running or offspring treadmill running on the spatial learning ability of adolescent offspring rats or adult offspring rats born to maternal rats that received stress during pregnancy. For this study, spatial learning ability was measured by radial 8-arm maze task. Immunohistochemistry for 5-bromo-2'-deoxyuridine and Western blot for brain-derived neurotrophic factor (BDNF), tyrosine kinase B (TrkB), Bcl-2-associated X protein (Bax), and B-cell lymphoma 2 (Bcl-2) were also conducted. Stress was induced by exposing pregnant rats to hound in an enclosed room. Maternal treadmill running or treadmill running of offspring improved spatial learning ability of adolescent and adult offspring rats born to maternal rats receiving stress during pregnancy. Maternal treadmill running or treadmill running of offspring increased hippocampal cell proliferation of adolescent and adult offspring rats born to maternal rats receiving stress during pregnancy. Maternal treadmill running or treadmill running of offspring increased BDNF and TrkB expression in the hippocampus of adolescent and adult offspring rats born to maternal rats receiving stress during pregnancy. Maternal treadmill running or treadmill running of offspring inhibited Bax expression and increased Bcl-2 expression in the hippocampus of adolescent and adult offspring rats born to maternal rats receiving stress during pregnancy. Mother's exercise during pregnancy or child's exercise after childbirth can improve the spatial learning ability deteriorated due to stress during pregnancy.

Keywords: Maternal stress, Treadmill exercise, Spatial learning ability, Cell proliferation, Brain-derived neurotrophic factor, Apoptosis

\section{INTRODUCTION}

Prenatal stress causes learning deficits by inhibiting neurogenesis in the hippocampus (Lemaire et al., 2000). Prenatal stress causes dysfunction of the hypothalamic-pituitary-adrenal axis, leading to impairment in fetal brain development (Maccari et al., 2003). Prenatal noise exposure retarded growth, decreased hippocampal neurogenesis, and disturbed spatial learning ability in rat pups, in contrast, prenatal music exposure increased hippocampal neurogenesis and improved spatial learning ability in rat pups (Kim et al., 2006). Radial 8-arm maze task has been used to measure spa- tial learning ability (Ko et al., 2019).

Immunohistochemistry for 5-bromo-2'-deoxyuridine ( $\mathrm{BrdU})$ is used to quantify the generation of new cells, and the neuronal nuclear antigen is a remarkable marker for verifying neuronal maturity (Ji et al., 2020). The hippocampus is where nerve cells are produced and is an important brain area that is implicated in learning and memory.

Enhancement of neurogenesis was not seen in brain-derived neurotrophic factor (BDNF) knockout mice (Rossi et al., 2006). BDNF is implicated in the neuronal differentiation and survival by binding to the receptor tyrosine kinase $\mathrm{B}(\operatorname{TrkB})$, and BDNF secretion
${ }^{*}$ Corresponding author: Sam-Jun Lee (iD https://orcid.org/0000-0002-8491-3602 Department of Sport Rehabilitation, College of Health, Welfare and Education, Tongmyong University, 428 Sinseon-ro, Nam-gu, Busan 48520, Korea Email: anada23@tu.ac.kr

Received: February 2, 2021 / Accepted: March 26, 2021
This is an Open Access article distributed under the terms of the Creative Commons Attribution Non-Commercial License (https://creativecommons.org/licenses/by-nc/4.0/) which permits unrestricted non-commercial use, distribution, and reproduction in any medium, provided the original work is properly cited. 
is regulated in an activity-dependent manner (Massa et al., 2010). BDNF signaling has an effect on neurotrophic support for neurons and also has an inhibitory effect on apoptosis (Neeley et al., 2011).

Apoptosis modulates tissue development and homeostasis. Manipulation of the B-cell lymphoma 2 (Bcl-2) family is helpful in the treatment of stroke and neurodegenerative diseases (Akhtar et al., 2004). The Bcl-2 family is divided into antiapoptotic proteins and pro-apoptotic proteins according to their function (Upadhyay et al., 2003). Bcl-2 inhibits cell death, whereas, Bcl-2-associated X protein (Bax) initiates cell death (Kuwana and Newmeyer, 2003).

We studied the effects of maternal treadmill running or offspring treadmill running on the spatial learning ability of adolescent offspring rats or adult offspring rats born to maternal rats that received stress during pregnancy. Spatial learning ability was evaluated by radial 8-arm maze task, and immunohistochemistry for BrdU and Western blot for BDNF, TrkB, Bax, and Bcl-2 were also done.

\section{MATERIALS AND METHODS}

\section{Adolescent and adult rats}

Adolescent and adult offspring Sprague-Dawley male rats were used for the experiment (Orient Co., Seoul, Korea). The pregnant rats were classified into the 3 following groups ( $n=5$ per group): the control group, the stress-induced group, and the stress-induced and exercise group. Offspring of the stress-induced group were classified into offspring of maternal stress group and offspring with exercise of maternal stress group. As a result, adolescent (280 \pm $10 \mathrm{~g}$ in weight, 12 weeks in age) and adult ( $320 \pm 10 \mathrm{~g}$ in weight, 24 weeks in age) offspring rats were randomly assigned into the 4 groups according to the status of maternal rats ( $\mathrm{n}=7$ in each group): offspring of control group, offspring of maternal stress group, offspring of maternal stress with exercise group, and offspring with exercise of maternal stress group. The pregnant rats received BrdU intraperitoneally $(100 \mathrm{mg} / \mathrm{kg}$, Sigma Chemical Co., St. Louis, MO, USA) once a day, 30 min before treadmill exercise, and 3 times per week for 2 weeks. Offspring rats also received $\mathrm{BrdU}(50 \mathrm{mg} / \mathrm{kg})$ intraperitoneally once a day, $30 \mathrm{~min}$ before treadmill exercises, for 2 weeks. For this experiment, approval number was achieved from the Institutional Animal Care and Use Committee of Tongmyong University (TMU-19-078).

\section{Inducing stress in pregnant rats}

Stress was induced by exposing pregnant rats to hound in an enclosed room. The exposure time to stress lasted for $10 \mathrm{~min}$, repeated 3 times a day at 1-hr intervals. Exposure of maternal rats to hound continued from pregnancy to delivery. The reaction of pregnant rats to hounds was observed from a distance, which included approaching, sniffing, and sometimes chasing with mild attacks. The hound could approach the pregnant rat, but could not harm the pregnant rat. The same hound was used throughout the experiment.

\section{Exercise protocol}

Pregnant rats in the exercise groups ran on a motorized treadmill for 30 min once a day, starting 7 days after pregnancy and continued until delivery. Offspring rats in the exercise group ran a motorized treadmill for 30 min once a day for 4 weeks. Exercise load was applied by running at a slope of $0^{\circ}$ at $2 \mathrm{~m} / \mathrm{min}$ for the first $5 \mathrm{~min}, 5 \mathrm{~m} / \mathrm{min}$ for the next $5 \mathrm{~min}$, and $8 \mathrm{~m} / \mathrm{min}$ for the last $20 \mathrm{~min}$.

\section{Radial 8-arm maze task}

Spatial learning ability was done by a radial 8-arm maze device, as mentioned in the below (Ko et al., 2019). The radial 8-arm maze device consisted of a central octagonal plate $(30 \mathrm{~cm}$ in diameter) and 8 radial arms (50 $\mathrm{cm}$ long, $10 \mathrm{~cm}$ wide), placed $1 \mathrm{~m}$ above the floor. There was a small container $3 \mathrm{~cm}$ in diameter and $1 \mathrm{~cm}$ in depth) filled with water at the end of the arm. The rats were deprived of water for $24 \mathrm{hr}$ before training or testing, and the rats were able to explore and drink the water for $5 \mathrm{~min}$. The rats were trained 3 times before taking the spatial learning ability test. On day 12 of the experiment, a spatial learning ability test was conducted. The time it took to find water at the tip of the arms was recorded, revisiting the previously visited arm was checked as error, and the visit before the first error was checked as correct. The experiment was finished when water was found in all 8-arms or 6 min of searching for water had passed.

\section{Tissue preparation}

After completing the radial 8-arm maze task, the rats were sacrificed mentioned in the below (Ko et al., 2019). Anesthesia was performed using Zoletil $50(10 \mathrm{mg} / \mathrm{kg}$, intraperitoneally; Vibac Laboratories, Carros, France) followed by infusion of $50 \mathrm{mM}$ phosphate-buffered saline (PBS) through the heart. The rats were fixed with $4 \%$ paraformaldehyde in $100 \mathrm{mM}$ phosphate buffer $(\mathrm{pH}$, 7.4). Brains were extracted and fixed overnight, then transferred to $30 \%$ sucrose solution for preventing freezing. Using a freezing microtome (Leica, Nussloch, Germany), 40- $\mu \mathrm{m}$ thick coronal sections, average 10 sliced sections, were made from the hippocampus of each rat. 


\section{Immunohistochemistry for BrdU}

BrdU immunohistochemistry was done, as mentioned in the below (Ji et al., 2020). After the sections were treated with $0.5 \%$ Triton X-100 in PBS for 20 min, incubated with 50\% formamide- $2 \mathrm{x}$ standard saline citrate at $65^{\circ} \mathrm{C}$ for $2 \mathrm{hr}$, denatured in $2 \mathrm{~N} \mathrm{HCl}$ for $30 \mathrm{~min}$ at $37^{\circ} \mathrm{C}$, and washed twice in $100 \mathrm{mM}$ sodium borate $(\mathrm{pH}, 8.5)$. Afterwards, the sections were incubated with BrdU-specific mouse monoclonal antibody (1:600; Roche, Mannheim, Germany) overnight at $4^{\circ} \mathrm{C}$. After washing 3 times with PBS, the sections were treated with biotinylated mouse secondary antibody (1:200; Vector Laboratories, Burlingame, CA, USA) for $1 \mathrm{hr}$. The sections were treated with an avidin-peroxidase complex (1:100; Vector Laboratories) for another $1 \mathrm{hr}$, treated with $50 \mathrm{mM}$ Tris- $\mathrm{HCl}(\mathrm{pH}, 7.6)$ containing $0.02 \%$ diaminobenzide, $40-\mathrm{mg} / \mathrm{mL}$ nickel chloride, and $0.03 \% \mathrm{H}_{2} \mathrm{O}_{2}$ in $50 \mathrm{mM}$ Tris$\mathrm{HCL}(\mathrm{pH}, 7.6)$ for $5 \mathrm{~min}$. BrdU-positive cells were confirmed by treating with a mouse antineuronal nuclear antibody (1:1,000; Chemicon International, Temecula, CA, USA). After washing 3 times with PBS, the sections were treated with a biotinylated anti-mouse secondary antibody for $\mathrm{l} \mathrm{hr}$, and then treated with a reaction mixture of $0.03 \%$ diaminobenzide with $0.03 \% \mathrm{H}_{2} \mathrm{O}_{2}$ for 5 min for staining.

\section{Western blot for BDNF, TrkB, Bax, and Bcl-2}

Western blot was done, as mentioned in the below (Ji et al., 2020). The hippocampal tissues were homogenized using lysis buffer consisting of $1 \mathrm{mM}$ EGTA, $1 \mathrm{mM}$ PMSF, $1 \mathrm{mM} \mathrm{Na}_{2} \mathrm{VO}_{4}$, $1.5 \mathrm{mM} \mathrm{MgCl} \cdot 6 \mathrm{H}_{2} \mathrm{O}, 50 \mathrm{mM}$ Tris- $\mathrm{HCl}(\mathrm{pH}, 8.0), 100 \mathrm{mM} \mathrm{NaF}$, $150 \mathrm{mM} \mathrm{NaCl}, 1 \%$ Triton X-100, 10\% glycerol, and then centrifuged at 50,000 rpm for $1 \mathrm{hr}$. Anti- $\beta$-actin antibody (1:2,000; Santa Cruz Biotechnology, Santa Cruz, CA, USA), anti-BDNF (1:1,000), anti-TrkB (1:1,000), anti-Bax antibody (1:1,000; Santa
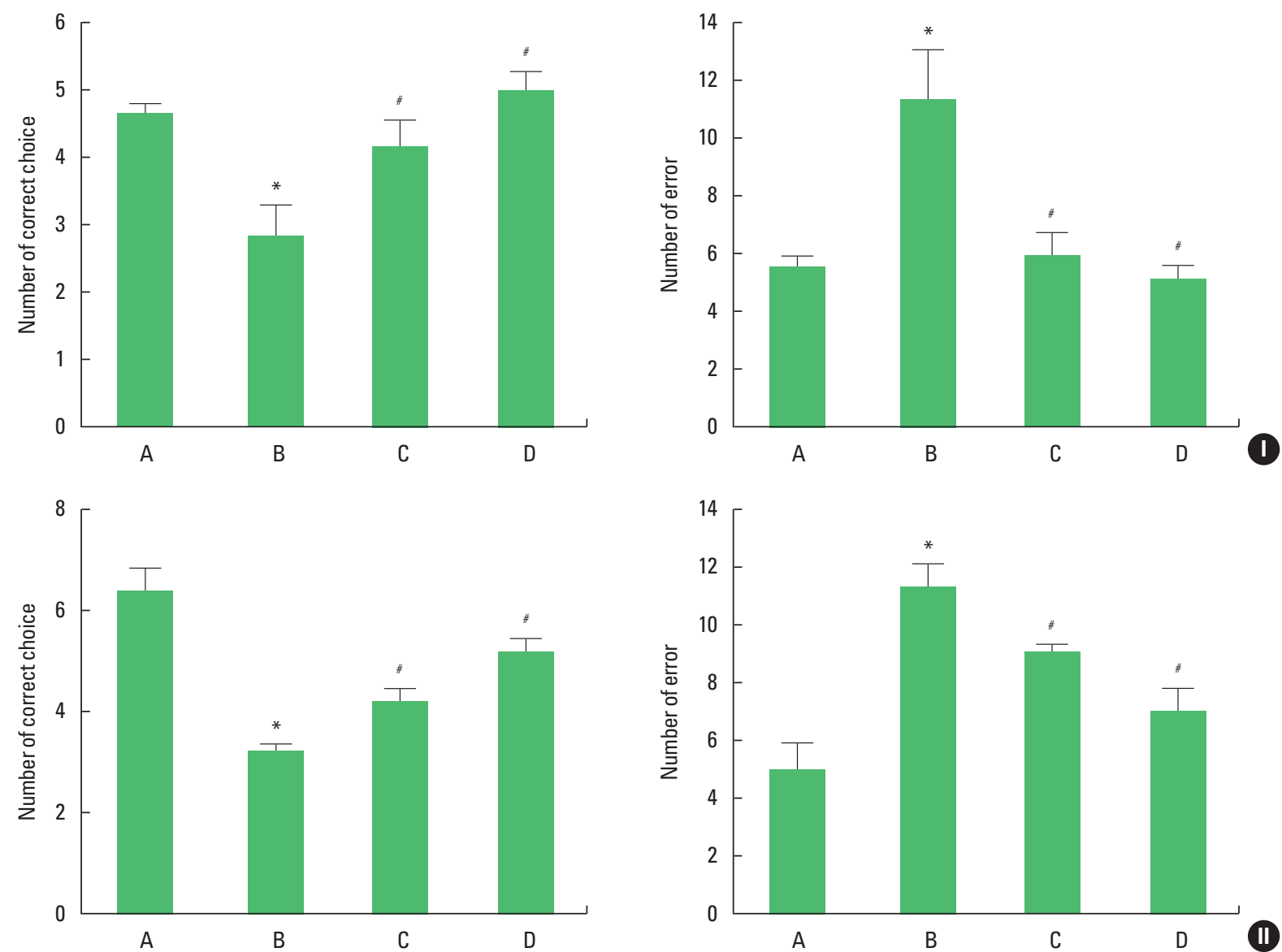

Fig. 1. Spatial memory of radial 8-arm maze in adolescent (I) and adult (II) offspring rats. Left panel: correct choice number. Right panel: error number. A, offspring of control group; B, offspring of maternal stress group; C, offspring of maternal stress with exercise group; D, offspring with exercise of maternal stress group. The results are expressed as the mean \pm standard error of the mean. ${ }^{*} P<0.05$ compared with offspring of control group. ${ }^{*} P<0.05$ compared with offspring of maternal stress group. 
Cruz Biotechnology), and anti-Bcl-2 antibody (1:1,000; Santa Cruz Biotechnology) were used as the primary antibodies. Horseradish peroxidase-conjugated anti-mouse antibody for $\beta$-actin, Bax, and Bcl-2 (1:3,000; Amersham Pharmacia Biothech GmbH, Freiburg, Germany), and horseradish peroxidase-conjugated anti-rabbit antibody for BDNF and TrkB (1:5,000; Vector Laboratories), were used as the secondary antibodies. In addition to the membrane transfer performed at $4^{\circ} \mathrm{C}$, all other steps were performed at room temperature. Band detection was done by enhanced chemiluminescence detection kit (Santa Cruz Biotechnology).

\section{Data analysis}

BrdU-positive cell number in the hippocampal dentate gyrus was calculated hemilaterally and presented as the number of cells per $\mathrm{mm}^{2}$. The detected band was measured with a densitometer. One-way analysis of variance followed by Duncan post hoc test was
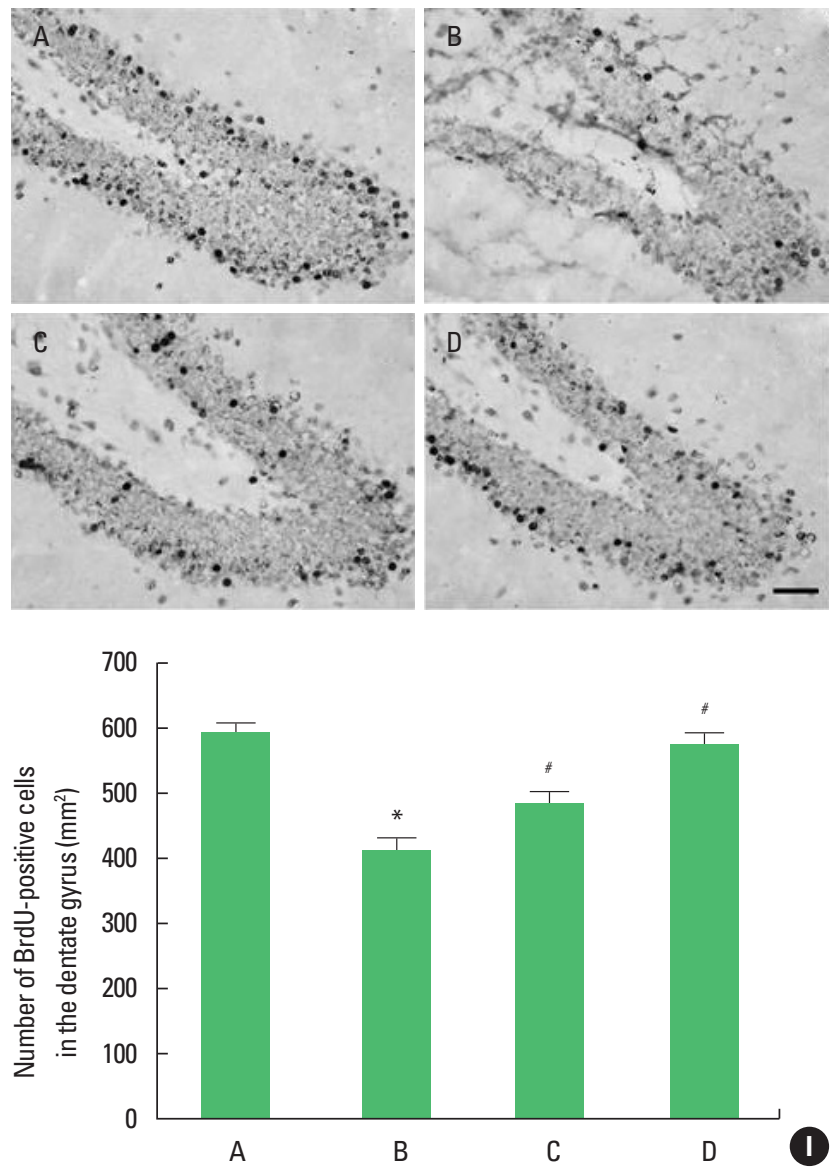

used for data analysis, and the data were presented as the mean \pm standard error of the mean. Statistically significance was determined at $P<0.05$.

\section{RESULTS}

\section{Spatial learning ability}

The results of radial 8-arm maze are shown in Fig. 1. Spatial learning ability of adolescent and adult offspring rats was deteriorated by stress during pregnancy. Maternal treadmill running during pregnancy or treadmill running of offspring restored learning ability of adolescent and adult offspring rats.

\section{Cell proliferation}

The results of BrdU immunohistochemistry are shown in Fig. 2. Cell proliferation of adolescent and adult offspring rats was sup-
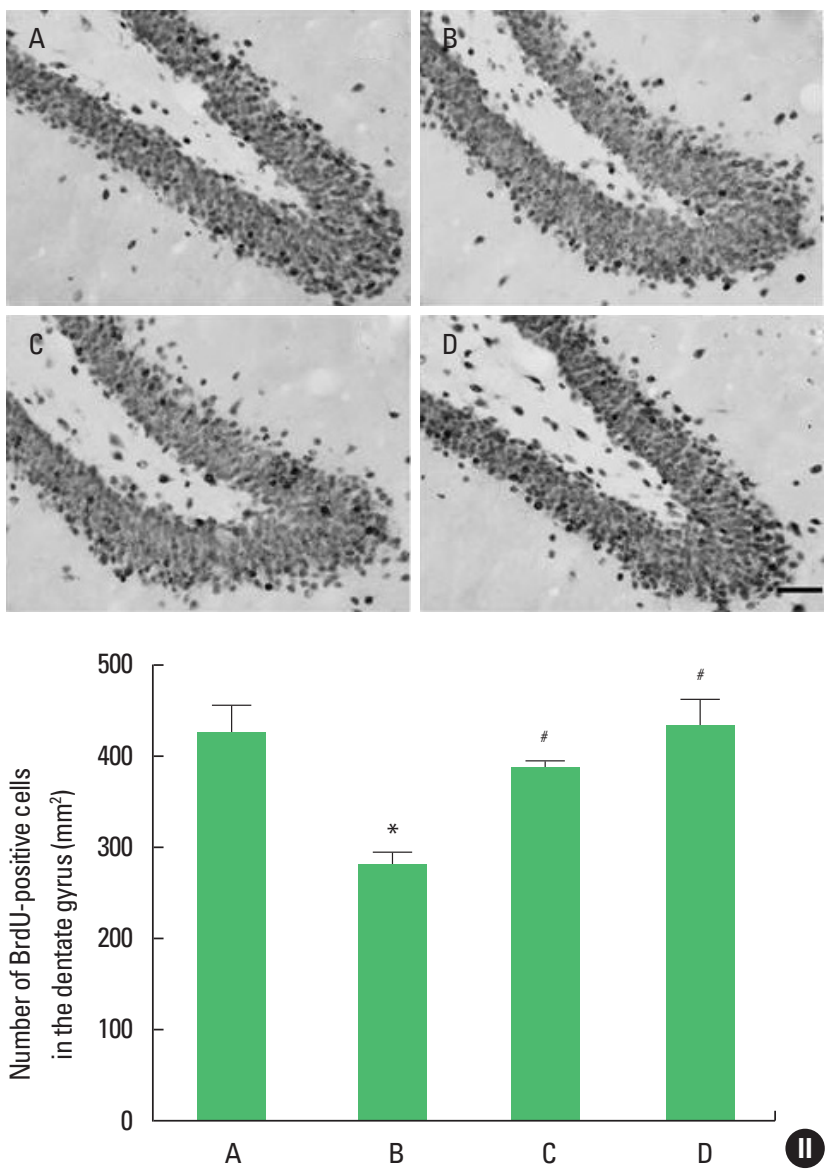

Fig. 2. Cell proliferation in the hippocampal dentate gyrus of adolescent (I) and adult (II) offspring rats. Upper panel: photomicrograph of 5-bromo-2'-deoxyuridine (BrdU)-positive cells. The scale bar represents $50 \mu \mathrm{m}$. Lower panel: number of BrdU-positive cells in each group. A, offspring of control group; $B$, offspring of maternal stress group; $C$, offspring of maternal stress with exercise group; $D$, offspring with exercise of maternal stress group. The results are expressed as the mean \pm standard error of the mean. ${ }^{*} P<0.05$ compared with offspring of control group. ${ }^{\sharp} P<0.05$ compared with offspring of maternal stress group. 
pressed by stress during pregnancy. Maternal treadmill running during pregnancy or treadmill running of offspring enhanced cell proliferation of adolescent and adult offspring rats.

\section{BDNF and TrkB expression}

The results of Western blot analysis for BDNF and TrkB expression in the hippocampus are shown in Fig. 3. BDNF and TrkB
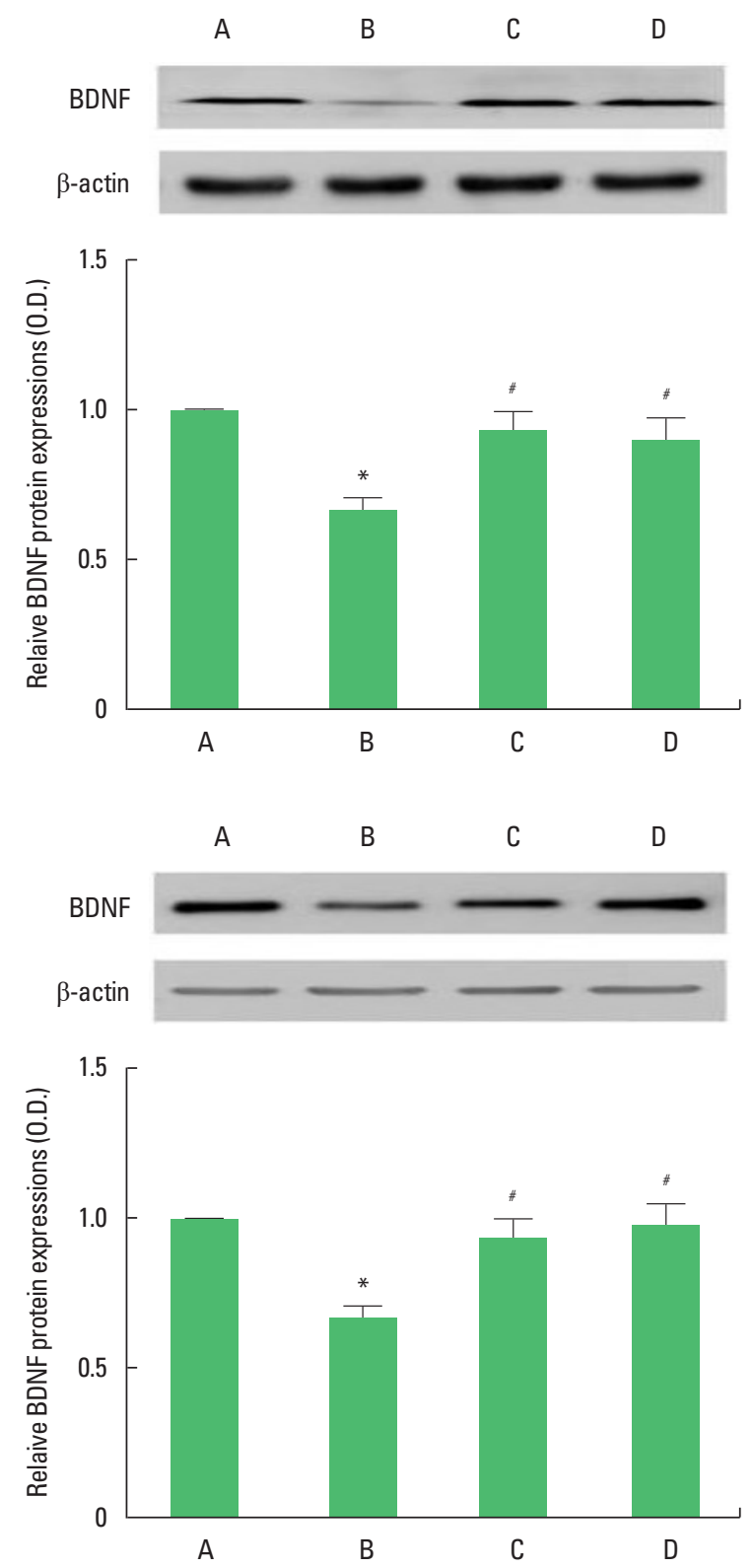

expression of adolescent and adult offspring rats was decreased by stress during pregnancy. Maternal treadmill running during pregnancy or treadmill running of offspring increased BDNF and TrkB expression of adolescent and adult offspring rats.

\section{Bax and $\mathrm{Bcl}-2$ expression}

The results of Western blot analysis for Bax and Bcl-2 expres-
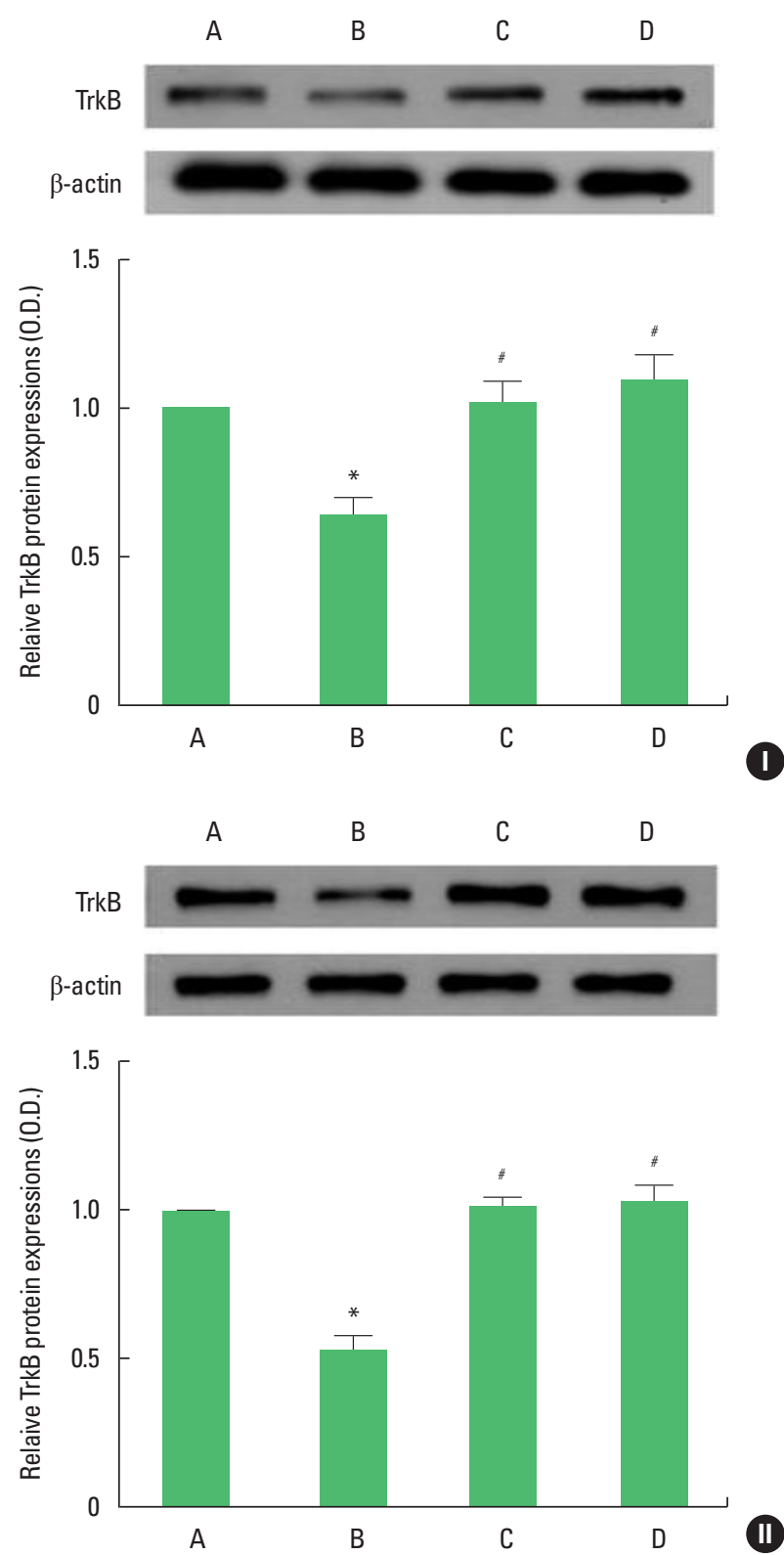

Fig. 3. Brain-derived neurotrophic factor (BDNF) and tyrosine kinase B (TrkB) expression in the hippocampus of adolescent (I) and adult (II) offspring rats. Upper panel: representative expression of BDNF or TrkB. Lower panel: expression of BDNF or TrkB in each group. A, offspring of control group; B, offspring of maternal stress group; $C$, offspring of maternal stress with exercise group; $D$, offspring with exercise of maternal stress group. The results are expressed as the mean \pm standard error of the mean. ${ }^{*} P<0.05$ compared with offspring of control group. ${ }^{\sharp} P<0.05$ compared with offspring of maternal stress group. 
sion in the hippocampus are shown in Fig. 4. Bax expression was enhanced and $\mathrm{Bcl}-2$ expression was inhibited in adolescent and adult offspring rats by stress during pregnancy. Maternal treadmill running during pregnancy or treadmill running of offspring was inhibited Bax expression and Bcl-2 expression was increased in adolescent and adult offspring rats.
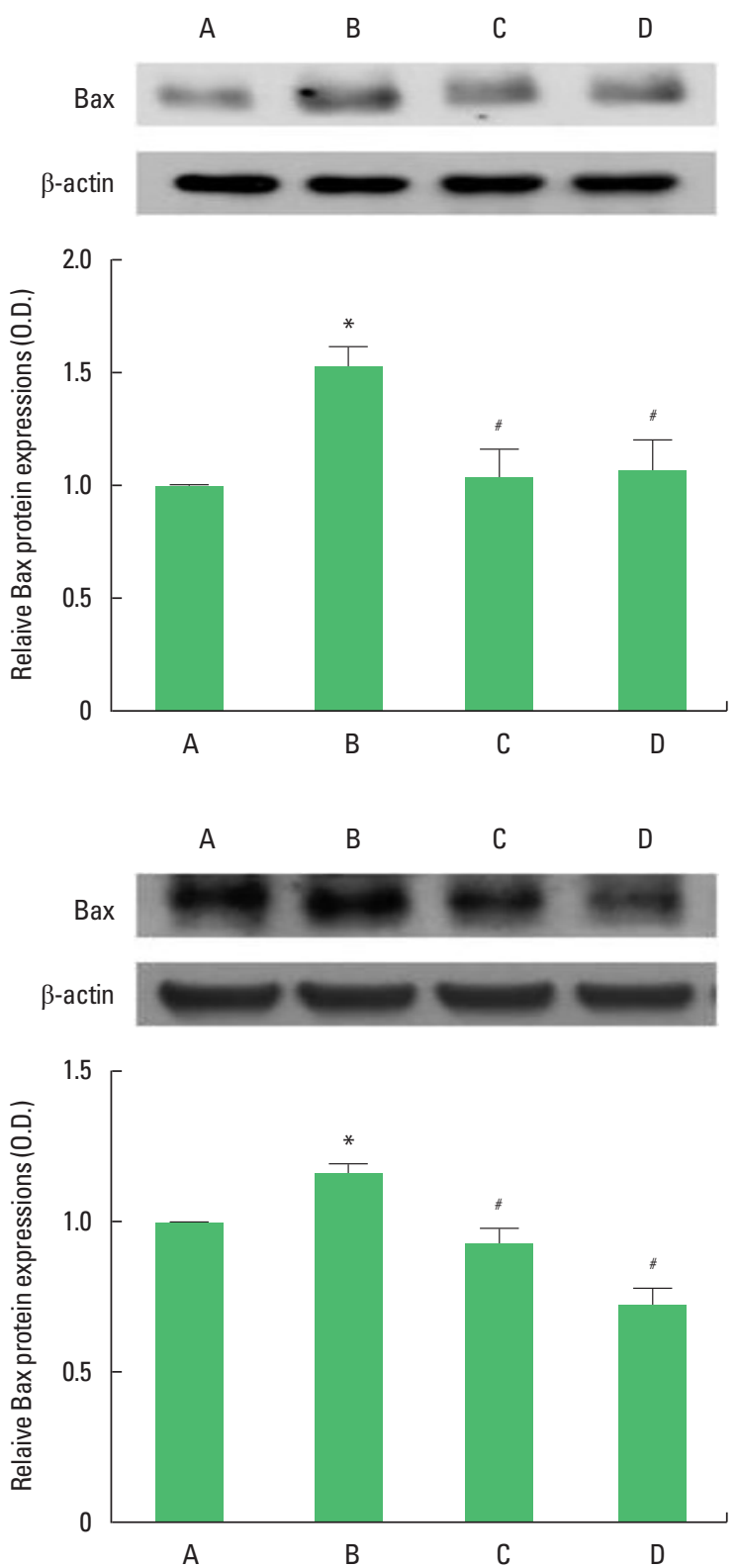

\section{DISCUSSION}

Early adversity can exacerbate amygdala and hippocampal dysfunction, and early intervention can mitigate early adversity-mediated reinforcement of hippocampal dysfunction (Imanaka et al., 2006). Maternal swimming during pregnancy enhanced shortterm memory with increasing neuronal proliferation in the hippo-
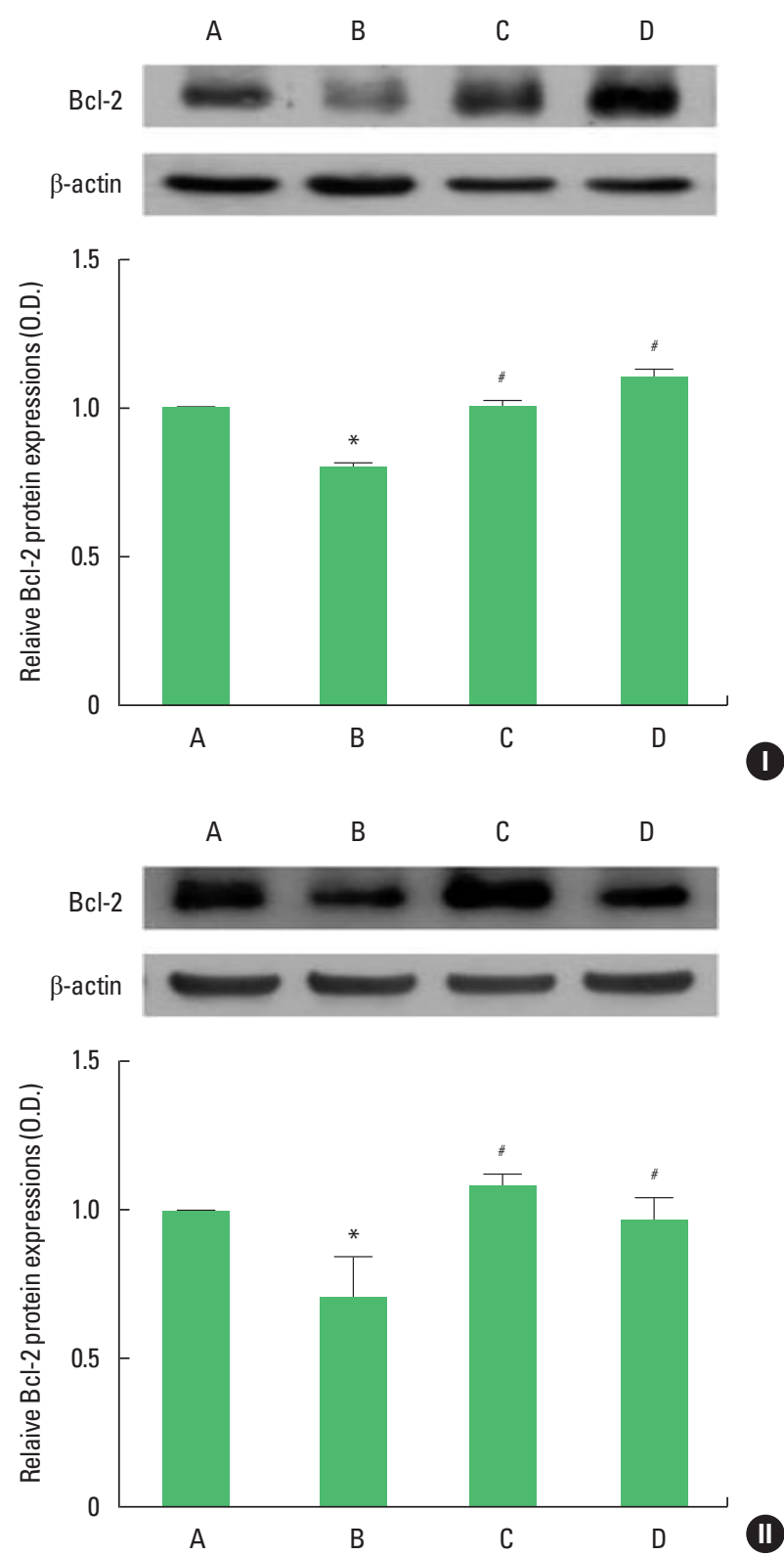

Fig. 4. Bcl-2-associated X protein (Bax) and B-cell lymphoma 2 (Bcl-2) expression in the hippocampus of adolescent (I) and adult (II) offspring rats. Upper panel: representative expression of Bax or Bcl-2. Lower panel: expression of Bax or Bcl-2 in each group. $\mathrm{A}$, offspring of control group; $\mathrm{B}$, offspring of maternal stress group; $\mathrm{C}$, offspring of maternal stress with exercise group; $D$, offspring with exercise of maternal stress group. The results are expressed as the mean \pm standard error of the mean. ${ }^{*} P<0.05$ compared with offspring of control group. ${ }^{\sharp} P<0.05$ compared with offspring of maternal stress group. 
campus of rat pups (Lee et al., 2006). Maternal treadmill running during pregnancy improved the short-term memory with increasing cell proliferation in the hippocampus of rat pups (Kim et al., 2007). Stress during pregnancy impaired the development of the fetus' brain, which has serious neurobiological effects after birth, leading to cognitive deficits (Kapoor et al., 2009). In the current results, spatial learning ability was impaired in adolescent and adult offspring rats born to maternal rats receiving stress during pregnancy. Maternal treadmill running or treadmill running of offspring improved spatial learning ability of adolescent and adult offspring rats born to maternal rats receiving stress during pregnancy.

Prenatal stress suppressed hippocampal cell proliferation in rats throughout their lifespan, suggesting that early stress exposure accelerated the age-related reduction in hippocampal plasticity (Lemaire et al., 2000). Wheel exercise increased hippocampal cell proliferation in socially housed rats, however, isolation prevented this running-induced increase of cell proliferation (Leasure and Decker, 2009). The chronic mild stress presented depression-like behaviors with inflammation, neuronal cell damage, and suppressed neurogenesis and apoptosis in the hippocampus (Kubera et al., 2011). In the current results, hippocampal cell proliferation was impaired in adolescent and adult offspring rats born to maternal rats receiving stress during pregnancy. Maternal treadmill running or treadmill running of offspring increased hippocampal cell proliferation of adolescent and adult offspring rats born to maternal rats receiving stress during pregnancy.

BDNF enhanced resistance to nerve injury, improved neuronal survival (Mizuno et al., 2000), and modulated neuronal generation in the hippocampus (Donovan et al., 2008). Neeley et al. (2011) showed that prenatal stress decreased BDNF and TrkB expression in the hippocampus.Treadmill running during pregnancy increased BDNF and TrkB expressions in rat pups born to obese maternal rats (Ji et al., 2020). They concluded that the effect of improving short-term memory by treadmill running could be attributed to enhanced neurogenesis through BDNF-TrkB activation by treadmill running (Ji et al., 2020). In the current results, BDNF and TrkB expression was decreased in the hippocampus of adolescent and adult offspring rats born to maternal rats receiving stress during pregnancy. Maternal treadmill running or treadmill running of offspring increased BDNF and TrkB expression in the hippocampus of adolescent and adult offspring rats born to maternal rats receiving stress during pregnancy.

$\mathrm{Bcl}-2$ overexpression improved neurogenesis and neuronal survival, suggesting that increased neurogenesis prevented the death of neonatal neurons (Zhang et al., 2006). Treadmill exercise inhibited expression of Bax and enhanced expression of $\mathrm{Bcl}-2$ in the brain-injured rats (Kim et al., 2010). Lee et al. (2011) reported that maternal exercise activated $\mathrm{Bcl}-2$ and inhibited Bax expression in the hyperthermia-induced apoptosis of the embryo. In the current results, Bax was enhanced and Bcl-2 was suppressed in adolescent and adult offspring rats born to maternal rats receiving stress during pregnancy. Maternal treadmill running or treadmill running of offspring inhibited Bax expression and increased Bcl-2 expression in the hippocampus of adolescent and adult offspring rats born to maternal rats receiving stress during pregnancy.

Through this experiment, it was proved that the mother's exercise during pregnancy or the child's exercise after childbirth can improve spatial learning ability when stressed during pregnancy. The effect of this exercise was achieved by hippocampal cell proliferation caused by enhancement of BDNF expression and inhibition of apoptosis.

\section{CONFLICT OF INTEREST}

No potential conflict of interest relevant to this article was reported.

\section{ACKNOWLEDGMENTS}

This work was supported by the Ministry of Education of the Republic of Korea and the National Research Foundation of Korea (NRF-2018S1A5A2A01038919).

\section{REFERENCES}

Akhtar RS, Ness JM, Roth KA. Bcl-2 family regulation of neuronal development and neurodegeneration. Biochim Biophys Acta 2004;1644:189203.

Donovan MH, Yamaguchi M, Eisch AJ. Dynamic expression of TrkB receptor protein on proliferating and maturing cells in the adult mouse dentate gyrus. Hippocampus 2008;18:435-439.

Imanaka A, Morinobu S, Toki S, Yamawaki S. Importance of early environment in the development of post-traumatic stress disorder-like behaviors. Behav Brain Res 2006;173:129-137.

Ji ES, Kim YM, Ko YJ, Baek SS. Treadmill exercise in obese maternal rats during pregnancy improves short-term memory through neurogenesis in the hippocampus of rat pups. J Exerc Rehabil 2020;16:392-397.

Kapoor A, Kostaki A, Janus C, Matthews SG. The effects of prenatal stress on learning in adult offspring is dependent on the timing of the stress- 
or. Behav Brain Res 2009;197:144-149.

Kim DH, Ko IG, Kim BK, Kim TW, Kim SE, Shin MS, Kim CJ, Kim H, Kim KM, Baek SS. Treadmill exercise inhibits traumatic brain injury-induced hippocampal apoptosis. Physiol Behav 2010;101:660-665.

Kim H, Lee MH, Chang HK, Lee TH, Lee HH, Shin MC, Shin MS, Won R, Shin HS, Kim CJ. Influence of prenatal noise and music on the spatial memory and neurogenesis in the hippocampus of developing rats. Brain Dev 2006;28:109-114.

Kim H, Lee SH, Kim SS, Yoo JH, Kim CJ. The influence of maternal treadmill running during pregnancy on short-term memory and hippocampal cell survival in rat pups. Int J Dev Neurosci 2007;25:243-249.

Ko IG, Kim CJ, Kim H. Treadmill exercise improves memory by up-regulating dopamine and down-regulating D2 dopamine receptor in traumatic brain injury rats. J Exerc Rehabil 2019;15:504-511.

Kubera M, Obuchowicz E, Goehler L, Brzeszcz J, Maes M. In animal models, psychosocial stress-induced (neuro) inflammation, apoptosis and reduced neurogenesis are associated to the onset of depression. Prog Neuropsychopharmacol Biol Psychiatry 2011;35:744-759.

Kuwana T, Newmeyer DD. Bcl-2-family proteins and the role of mitochondria in apoptosis. Curr Opin Cell Biol 2003;15:691-699.

Leasure JL, Decker L. Social isolation prevents exercise-induced proliferation of hippocampal progenitor cells in female rats. Hippocampus 2009;19:907-912.

Lee HH, Kim H, Lee JW, Kim YS, Yang HY, Chang HK, Lee TH, Shin MC, Lee MH, Shin MS, Park S, Baek S, Kim CJ. Maternal swimming during pregnancy enhances short-term memory and neurogenesis in the hippocampus of rat pups. Brain Dev 2006;28:147-154.

Lee J, Cho JY, Oh SD, Kim SM, Shim YT, Park S, Kim WK. Maternal exercise reduces hyperthermia-induced apoptosis in developing mouse brain. Int J Hyperthermia 2011;27:445-452.
Lemaire V, Koehl M, Le Moal M, Abrous DN. Prenatal stress produces learning deficits associated with an inhibition of neurogenesis in the hippocampus. Proc Natl Acad Sci U S A 2000;97:11032-11037.

Maccari S, Darnaudery M, Morley-Fletcher S, Zuena AR, Cinque C, Van Reeth O. Prenatal stress and long-term consequences: implications of glucocorticoid hormones. Neurosci Biobehav Rev 2003;27:119-127.

Massa SM, Yang T, Xie Y, Shi J, Bilgen M, Joyce JN, Nehama D, Rajadas J, Longo FM. Small molecule BDNF mimetics activate TrkB signaling and prevent neuronal degeneration in rodents. J Clin Invest 2010;120: 1774-1785.

Mizuno M, Yamada K, Olariu A, Nawa H, Nabeshima T. Involvement of brain-derived neurotrophic factor in spatial memory formation and maintenance in a radial arm maze test in rats. J Neurosci 2000;20:71167121.

Neeley EW, Berger R, Koenig JI, Leonard S. Prenatal stress differentially alters brain-derived neurotrophic factor expression and signaling across rat strains. Neuroscience 2011;187:24-35.

Rossi C, Angelucci A, Costantin L, Braschi C, Mazzantini M, Babbini F, Fabbri ME, Tessarollo L, Maffei L, Berardi N, Caleo M. Brain-derived neurotrophic factor (BDNF) is required for the enhancement of hippocampal neurogenesis following environmental enrichment. Eur J Neurosci 2006;24:1850-1856.

Upadhyay D, Panduri V, Ghio A, Kamp DW. Particulate matter induces alveolar epithelial cell DNA damage and apoptosis: role of free radicals and the mitochondria. Am J Respir Cell Mol Biol 2003;29:180-187.

Zhang R, Xue YY, Lu SD, Wang Y, Zhang LM, Huang YL, Signore AP, Chen J, Sun FY. Bcl-2 enhances neurogenesis and inhibits apoptosis of newborn neurons in adult rat brain following a transient middle cerebral artery occlusion. Neurobiol Dis 2006;24:345-356. 